\title{
Factors influencing the quality of nursing care as perceived by mothers of hospitalized children in South Korea
}

\author{
Ina $\mathrm{Jin}^{1}$, Hun Ha Cho ${ }^{2}$ \\ ${ }^{1}$ Head Nurse, Busan Children's Hospital, Busan; ${ }^{2}$ Assistant Professor, College of Nursing, Kosin University, Busan, Korea
}

Purpose: This study aimed to identify the factors affecting the quality of nursing care as perceived by mothers of hospitalized children and provide basic data for the development of nursing care quality improvement programs. Methods: The participants consisted of 167 mothers, each of whom had a child hospitalized at a specific children's hospital. Data were collected from June 22 to August 8, 2019. Results: The factors that affected how mothers perceived the quality of nursing care were the communication ability of nurses $(\beta=.44, p<.001)$ and the mother-nurse partnership $(\beta=.33, p=.001)$. The total explanatory power of these factors was $54.1 \%$. Conclusion: To improve the quality of pediatric nursing care, it is necessary to improve the communication abilities of nurses and to promote partnership between nurses and the mothers of hospitalized children.

Key words: Communication; Mothers; Partnership; Quality of health care; Uncertainty

\author{
Corresponding author \\ Hun Ha Cho \\ College of Nursing, Kosin University, 262 \\ Gamcheon-ro, Seo-gu, Busan 49267, \\ Korea \\ TEL: +82-51-990-3959 \\ FAX: +82-51-990-3970 \\ E-MAIL: hhuna@kosin.ac.kr
}

\begin{abstract}
This article was adapted from a thesis by Ina Jin in partial fulfillment of the requirements for students to write a master's degree at Kosin University of Korea
\end{abstract}

Received May 23, 2021

Revised Jun 20, 2021

Accepted Jun 27, 2021

\section{INTRODUCTION}

In recent years, the social phenomenon of a declining birth rate, resulting in a relatively low population of children, has emerged as a serious national problem in South Korea [1]. Despite the low birth rate, however, medical expenses for children and adolescents are increasing [2]. This reflects the increased use of medical services due to the expansion of health insurance coverage and parents' greater interest and sensitivity to their children's health.

Since pediatric nurses must provide individualized care to children according to their conditions, developmental status, and age, particular caution should be observed when providing nursing care to this population [3]. Moreover, when a child is hospitalized, both the child and the caregiver experience changes related to hospitalization and have various additional needs [3]. Therefore, pediatric nurses must provide nursing care that addresses both the child and their caretakers.
Positive outcomes have been observed when parents' nursing care needs for their child are met, such as the child's rapid recovery from his or her condition, reduced anxiety, burden, and stress in mothers and guardians, and satisfaction with nursing services [4-6]. Therefore, to provide high-quality nursing care for children and families and increase their satisfaction with nursing services, it is necessary to identify the factors that affect the quality of nursing care [4].

The quality of nursing care affects several variables such as patients' treatments and the need for re-hospitalization, which underscores its importance [6,7]. The quality of nursing care perceived by mothers of hospitalized children is affected by the communication ability of nurses, the mother-nurse partnership, and the degree of uncertainty felt by mothers of hospitalized children [8-10].

To ensure effective nursing care, nurses should cultivate relationships with patients through close interaction; thus, communication is a very important factor [3,4]. In particular, the 
communication abilities of children are limited due to their age, and pediatric nurses must collaborate with children's caretakers using effective communication in order to provide quality nursing care [3]. Pediatric nurses' communication abilities enable them to understand the needs and emotions of children and their caregivers, which is essential for improving the quality of pediatric nursing care [4]. Effective communication between children's parents and medical personnel not only enhances hospitalized children's satisfaction with healthcare, but also affects health promotion and long-term adherence to treatment [11].

Since children's ability to collaborate is limited due to their developmental status, the mother-nurse partnership-meaning mutual collaboration between nurses and mothers of hospitalized children-is important for children's health management [3]. It has been found that mothers tend to give a high rating to the quality of nursing care, children's adherence to treatment, and their ability to manage their child's condition when they had a positive perception of the mother-nurse partnership $[9,12]$.

When the mother of a hospitalized child is uncertain about the status of her child's health and hospitalization due to a lack of knowledge about her child's condition, the unpredictability of the treatment process, and disease prognosis, this may result in anxiety and fears that in turn negatively affect the course of treatment [13]. Parents of children hospitalized with acute diseases tend to experience a high degree of uncertainty and require more nursing care, while their satisfaction with nursing care and their evaluation of the quality of nursing care is more likely to remain low [10].

Studies on the quality of nursing care, however, have mostly focused on adults, including a study on the relationship between the quality of nursing care as perceived by parents, satisfaction with medical treatment, and the need for inpatient re-hospitalization [7] and another on the factors that influence of nursing care satisfaction [14]. Studies on the quality of nursing care conducted after the development of a tool for measuring the quality of nursing care for hospitalized children with acute diseases and their families [15] included a study that examined the effect of the mother-nurse partnership on anxiety and quality of nursing care as perceived by mothers of hospitalized children [9] and another comparative study of the quality of nursing care as perceived by pediatric nurses and the mothers of hospitalized children with acute diseases [16]. However, relatively few studies have investigated these issues.

Although some studies have examined the fragmentary relationship between the communication ability of nurses, the mother-nurse partnership, uncertainty, and the quality of nursing care perceived by mothers of hospitalized children, no studies have explored the integrated relationship between these variables and the quality of nursing care. Therefore, this study examined the effects of the communication ability of nurses, the mother-nurse partnership, and uncertainty on the quality of nursing care as perceived by mothers of hospitalized children.

\section{METHODS}

Ethics statement: This study was approved by the institutional review board of Kosin University(No. KU IRB 2019-0031). Informed consent was obtained from the participants.

\section{Study Design}

This descriptive study aimed to investigate the quality of nursing care as perceived by mothers of hospitalized children.

\section{Subjects}

The study participants were mothers of children hospitalized at a 60-bed children's hospital that used a modified primary nursing delivery system located in Busan, South Korea. The specific selection criteria were mothers of children who had been hospitalized for more than 2 days with an acute illness [17] and those who understood the purpose of this study and agreed to participate in this study. The exclusion criterion was mothers of hospitalized children with intractable and severe disease [15].

The sample size required for this study was calculated using the $G^{*}$ Power 3.1.9.2 program. Using a power (1- $\beta$ ) of $80 \%$, assuming a significance level of $\alpha=.05$ and an effect size (medium) of .15, which is required for multiple regression analysis, and 17 predictors, the sample size was calculated to be 146 subjects. Given an expected dropout rate of $20 \%$, data from 180 participants were collected [18]. After excluding eight questionnaires that had incomplete information and five that were not returned, data from 167 questionnaires were used for the final analysis.

\section{Instruments}

\section{1) The communication ability of nurses}

The communication ability of nurses was measured using a tool developed for medical service providers by Kim and $\mathrm{Yu}$ [19] and modified for nurses by Kim [8]. It consists of 13 items with four items on verbal communication and nine items on non-verbal communication that are rated on a 5-point Likert 
scale; a higher score indicates that the perceived communication abilities of nurses were better as perceived by mothers of hospitalized children. The reliability of this tool was indicated by a Cronbach's $\alpha$ of .82 in the study by Kim and Yu [19], 93 in the study by Kim [8], and .96 in this study.

\section{2) Mother-nurse partnership}

Mother-nurse partnership was measured using the Pediatric Nurse-Parent Partnership Scale developed by Choi and Bang [20]. This tool consists of 34 items with seven subdomains that address reciprocity, professional knowledge and skills, sensitivity, collaboration, communication, shared information, and cautiousness. Items are rated on a 5-point Likert scale; a higher score indicates a better partnership between nurses and the mothers of hospitalized children. The reliability of this tool was indicated by a Cronbach's $\alpha$ of .96 in the study by Choi and Bang [20] and .97 in this study.

\section{3) Uncertainty}

Uncertainty was measured using a tool that was translated and modified by Oh [13] based on the Parents' Perception of Uncertainty Scale developed by Mishel [21]. It consists of 22 items with 10 items on ambiguity, eight items on unpredictability related to the inability to foresee the progression of the disease, and four items on the reliability of medical personnel. It is rated on a 4-point Likert scale, and a higher score indicates a higher level of uncertainty. The reliability of the tool was indicated by a Cronbach's $\alpha$ of .91 in the study by Mishel [21], .83 in the study by Oh [13], and .86 in this study.

\section{4) Quality of nursing care}

The quality of nursing care perceived by mothers of hospitalized children was measured using the Quality of Care Through the Patient's Eyes-Child (QUOTE-Child) developed by Cho et al. [15]. It consists of 19 items with six items on respect, seven items on explanation, three items on kindness, and three items on skillfulness. Items assessing the importance of nursing care and nursing performance as perceived by mothers of hospitalized children are measured on a 4-point Likert scale; higher scores indicate a greater belief in the importance of nursing care and a better nursing performance.

Items assessing the importance of nursing care are given scores of 0 points for "not important" (1), 3 points for "a little important" (2), 6 points for "important" (3), and 10 points for "very important" (4). The collected scores for nursing performance are converted to 1 point for "disagree completely" (1), 0.67 points for "disagree" (2), 0.33 points for "largely agree" (3), and 0 points for "agree." Scores measuring the quality of nurs- ing care are calculated using the formula 10 -(score for importance $\times$ score for performance). Total possible scores range from 0 to 10 points. A higher score indicates a higher quality of nursing care. In the study by Cho et al., the reliability of the tool for measuring the importance of nursing care was indicated by a Cronbach's $\alpha$ of .93, while Cronbach's $\alpha$ was .96 for the tool for measuring nursing performance [15]. In this study, the reliability of the tools for measuring the importance of nursing and nursing performance was indicated by Cronbach's $\alpha$ values of .93 and .94, respectively.

\section{Data Collection}

Data were collected from June 22, 2019, to August 8, 2019. After receiving approval from the institutional review board (No. KU IRB 2019-0031) at Kosin University, located in Busan, South Korea, the researcher visited a children's hospital in Busan to explain the purpose and procedures of this study and received permission from the hospital for data collection. Participants who met the selection criteria were also informed about the purpose and procedures of this study and were asked to provide written informed consent to participate. Participants were subsequently asked to complete a self-report questionnaire.

Since it is difficult to control factors that affect the quality of nursing care in various hospital environments, a single-institution study was conducted to ensure the validity of the study results. Thus, it is difficult to generalize the results of this study for mothers of hospitalized children in other children's hospitals. Nonetheless, this study meaningfully identified the factors that influence the quality of care and provided basic data for the development of programs to improve the quality of nursing care for hospitalized children.

\section{Data Analysis}

The data were analyzed using SPSS/WIN 23.0 (IBM Corp., Armonk, NY, USA). The general characteristics of participants were analyzed using descriptive statistics. The communication ability of nurses, the mother-nurse partnership, uncertainty, and the quality of nursing care perceived by participants were analyzed to determine the mean, standard deviation, and minimum and maximum values. The quality of nursing care according to the general characteristics of participants was analyzed using the t-test and one-way analysis of variance (ANOVA). The relationships between major variables were analyzed using the Pearson correlation coefficient. The factors that affected the quality of nursing care perceived by participants were analyzed using stepwise multiple regression. 


\section{RESULTS}

\section{General Characteristics of Mothers and Their Children}

The mean age of the participants was $34.9 \pm 4.8$ years old. Most of the participants were aged between 30 and 40 years old $(76.6 \% ; n=128)$ and were college graduates $(76.0 \% ; n=127)$. Almost half of the participants $(49.1 \%$; $n=82)$ had only one child was the highest. Slightly more than half $(52.1 \%$; $=87)$ of the participants reported that they did not practice any religion, and $54.5 \%(n=91)$ were unemployed. For income, the proportion of those with a monthly family income of over 5,000,000 won was the highest $(35.9 \% ; n=60)$. Additionally, $71.3 \%(n=119)$ of participants were helped by another caregiver.

The highest proportion of hospitalized children (32.2\%; $\mathrm{n}=54$ ) were aged between 12 months and 24 months. Most of the children were the first-born child $(59.9 \%$; $=100)$, and $54.5 \%(n=91)$ were male. Mothers were the primary caregiver for most of the children $(94 \% ; n=157)$. Bronchitis was the most common diagnosis among the children $(26.9 \%$; $n=45)$, followed by pneumonia, stomatitis, tonsillitis, and acute gastroenteritis. The largest proportion of children had more than four hospitalizations $(37.1 \%$; $=62)$ (Table 1$)$.

\section{Communication Ability of Nurses, the Mother-Nurse Partnership, Uncertainty, and Quality of Nursing Care Perceived by Participants}

The mean score for the communication ability of nurses as perceived by participants was $4.59 \pm 0.49$ points (out of 5 points). In addition, the mean score for the mother-nurse partnership as perceived by participants was $4.39 \pm 0.53$ points (out of 5 points), while the mean score for uncertainty perceived by participants was $2.03 \pm 0.35$ points (out of 4 points). Lastly, the mean score for the quality of nursing care perceived by participants was $9.16 \pm 0.93$ points (with possible scores ranging from 0 to 10) (Table 2).

\section{Differences in the Quality of Nursing Care According to the General Characteristics of Participants}

No statistically significant differences were observed after examining the differences in the quality of nursing care according to the general characteristics of participants (Table 1).

\section{Correlation between the Communication Ability of Nurses, the Mother-Nurse Partnership, Uncertainty, and Quality of Nursing Care Perceived by Participants}

There was a statistically significant positive correlation be- tween the quality of nursing care perceived by participants and the communication ability of nurses $(\mathrm{r}=.71, p<.001)$, as well as between the quality of nursing care and the mother-nurse partnership $(\mathrm{r}=.69, p<.001)$. There was a significant negative correlation between the quality of nursing care and uncertainty $(\mathrm{r}=-.33, p<.001)$ (Table 3$)$.

\section{Factors Influencing the Quality of Nursing Care Per- ceived by Participants}

To identify the factors affecting the quality of nursing care perceived by participants, stepwise multiple regression analysis was performed for the communication ability of nurses, the mother-nurse partnership, and uncertainty, which were found to be related to the quality of nursing care in correlation analysis.

Testing for multicollinearity in multiple regression analysis to test the assumptions for the independent variables revealed that the tolerance limit value in the regression analysis ranged from 0.31 to 1.00 , which was higher than 1 , and the variance inflation factor value ranged from 1.00 to 3.22 , indicating that there was no multicollinearity between the independent variables. The Durbin-Watson statistic was calculated to test the independence of the residuals, resulting in a value of 1.99 , which was close to 2 , indicating that there was no autocorrelation.

The factors affecting the quality of nursing care perceived by participants were the communication ability of nurses $(\beta=.44$, $p<.001)$ and the mother-nurse partnership $(\beta=.33, p=.001)$. The total explanatory power of these variables for the quality of nursing care was $54.1 \%$ (Table 4 ).

\section{DISCUSSION}

This study aimed to investigate the relationship between the communication ability of nurses, the mother-nurse partnership, uncertainty, and the quality of nursing care perceived by mothers of hospitalized children, as well as the effects of variables on the quality of nursing care as perceived by mothers of hospitalized children.

The mean score for the quality of nursing care perceived by mothers of hospitalized children (mean=9.16, with a possible score range of 0-10) was higher than those of studies by Bae and Lee [9] (mean=8.65) and Cho et al. [15] (mean=7.56) that used the same tool. These differences are perhaps due to differences in the nursing care delivery systems between hospitals. Although most wards and university hospitals generally provide nursing care through functional nursing and team nursing delivery systems [22], the children's hospital at which this study was conducted provided nursing care using a mo- 
Table 1. General Characteristics of Participants and Scores for Quality of Nursing Care $(N=167)$

\begin{tabular}{|c|c|c|c|c|c|c|c|}
\hline \multirow{2}{*}{\multicolumn{2}{|c|}{ Characteristics }} & \multirow{5}{*}{$\begin{array}{l}\text { Categories } \\
\begin{array}{l}<30 \\
\geq 30 \&<40 \\
\geq 40\end{array}\end{array}$} & \multirow{3}{*}{$\begin{array}{c}\mathrm{n}(\%) \\
16(9.6)\end{array}$} & \multirow{3}{*}{$\begin{array}{c}\mathrm{M}+\mathrm{SD} \\
34.9 \pm 4.8\end{array}$} & \multicolumn{3}{|c|}{ Quality of nursing care } \\
\hline & & & & & \multirow{4}{*}{$\begin{array}{c}\mathrm{M}+\mathrm{SD}^{*} \\
9.44 \pm 0.78 \\
9.15 \pm 0.92 \\
8.95 \pm 1.04\end{array}$} & \multirow{2}{*}{$\begin{array}{c}\text { t or } F \\
1.30\end{array}$} & \multirow{2}{*}{$\begin{array}{c}p \\
.274\end{array}$} \\
\hline \multirow[t]{20}{*}{ Mother } & Age (year) & & & & & & \\
\hline & & & $128(76.6)$ & & & & \\
\hline & & & $23(13.8)$ & & & & \\
\hline & Education & $\leq$ High school graduate & 31 (18.6) & & $9.25 \pm 0.81$ & 1.09 & .338 \\
\hline & & College graduate & $127(76.0)$ & & $9.17 \pm 0.94$ & & \\
\hline & & $\geq$ Graduate school & $9(5.4)$ & & $8.74 \pm 1.12$ & & \\
\hline & Number of children & 1 & $82(49.1)$ & $1.62 \pm 0.70$ & $9.06 \pm 1.01$ & 0.92 & .401 \\
\hline & & 2 & $68(40.7)$ & & $9.25 \pm 0.87$ & & \\
\hline & & $\geq 3$ & $17(10.2)$ & & $9.27 \pm 0.73$ & & \\
\hline & Religion & Yes & $80(47.9)$ & & $9.10 \pm 0.95$ & 0.71 & .476 \\
\hline & & No & $87(52.1)$ & & $9.21 \pm 0.91$ & & \\
\hline & Employment & Employed & $76(45.5)$ & & $9.15 \pm 0.93$ & 0.12 & .907 \\
\hline & status & Unemployed & $91(54.5)$ & & $9.17 \pm 0.93$ & & \\
\hline & Family income & $<200$ & $7(4.2)$ & & $8.75 \pm 0.96$ & 1.89 & .114 \\
\hline & (10,000 won) & $\geq 200 \&<300$ & $21(12.6)$ & & $8.98 \pm 0.93$ & & \\
\hline & & $\geq 300 \&<400$ & $42(25.1)$ & & $8.98 \pm 0.99$ & & \\
\hline & & $\geq 400 \&<500$ & $37(22.2)$ & & $9.16 \pm 0.96$ & & \\
\hline & & $\geq 500$ & $60(35.9)$ & & $9.39 \pm 0.83$ & & \\
\hline & Received help from & Yes & $119(71.3)$ & & $9.21 \pm 0.91$ & 1.17 & .245 \\
\hline & another caregiver & No & $48(28.7)$ & & $9.03 \pm 0.98$ & & \\
\hline \multirow[t]{26}{*}{ Child } & Age (month) & $<12$ & $22(13.2)$ & $35.9 \pm 29.5$ & $8.87 \pm 1.01$ & 1.32 & .266 \\
\hline & & $\geq 12 \&<24$ & $54(32.2)$ & & $9.05 \pm 0.97$ & & \\
\hline & & $\geq 24 \&<36$ & $34(20.4)$ & & $9.19 \pm 0.92$ & & \\
\hline & & $\geq 36 \&<48$ & $23(13.8)$ & & $9.37 \pm 0.87$ & & \\
\hline & & $\geq 48$ & $34(20.4)$ & & $9.33 \pm 0.83$ & & \\
\hline & Birth order & First & $100(59.9)$ & & $9.15 \pm 0.97$ & 0.08 & .923 \\
\hline & & Second & 55 (32.9) & & $9.19 \pm 0.90$ & & \\
\hline & & $\geq$ Third & $12(7.2)$ & & $9.07 \pm 0.78$ & & \\
\hline & Sex & Male & $91(54.5)$ & & $9.22 \pm 0.89$ & 0.92 & .360 \\
\hline & & Female & $76(45.5)$ & & $9.09 \pm 0.97$ & & \\
\hline & Caregiver & Mother & $157(94.0)$ & & $9.14 \pm 0.93$ & 1.09 & .275 \\
\hline & & Other & $10(6.0)$ & & $9.47 \pm 0.95$ & & \\
\hline & Diagnosis & Bronchitis & $45(26.9)$ & & $9.17 \pm 0.95$ & 0.81 & .544 \\
\hline & & Pneumonia & $34(20.4)$ & & $9.28 \pm 0.87$ & & \\
\hline & & Stomatitis & 33 (19.7) & & $9.07 \pm 0.95$ & & \\
\hline & & Tonsillitis & $28(16.8)$ & & $9.30 \pm 0.89$ & & \\
\hline & & Acute gastroenteritis & $14(8.4)$ & & $8.77 \pm 1.06$ & & \\
\hline & & Other & $13(7.8)$ & & $9.13 \pm 0.96$ & & \\
\hline & Hospitalization period & 2 & $56(33.5)$ & $3.14 \pm 1.10$ & $9.13 \pm 0.98$ & 0.07 & .978 \\
\hline & (day) & 3 & $57(34.1)$ & & $9.20 \pm 0.96$ & & \\
\hline & & 4 & $34(20.4)$ & & $9.16 \pm 0.82$ & & \\
\hline & & $\geq 5$ & $20(12.0)$ & & $9.11 \pm 0.95$ & & \\
\hline & Number of & 1 st & $34(20.3)$ & $3.67 \pm 3.10$ & $9.04 \pm 1.00$ & 0.61 & .607 \\
\hline & hospitalizations & 2nd & $41(24.6)$ & & $9.08 \pm 0.85$ & & \\
\hline & & $3 \mathrm{rd}$ & $30(18.0)$ & & $9.14 \pm 1.03$ & & \\
\hline & & $\geq 4$ th & $62(37.1)$ & & $9.28 \pm 0.90$ & & \\
\hline
\end{tabular}

\footnotetext{
*Average conversion score.
} 
Table 2. Scores for the Communication Ability of Nurses, the Mother-Nurse Partnership, Uncertainty, and the Quality of Nursing Care $(N=167)$

\begin{tabular}{|c|c|c|c|c|}
\hline Variables & $\mathrm{M} \pm \mathrm{SD}$ & Min-Max & $\mathrm{M} \pm \mathrm{SD}^{*}$ & Range \\
\hline Communication ability of nurses & $59.63 \pm 6.37$ & $40-65$ & $4.59 \pm 0.49$ & $1-5$ \\
\hline Verbal communication ability & $18.11 \pm 2.22$ & $12-20$ & $4.53 \pm 0.55$ & $1-5$ \\
\hline Non-verbal communication ability & $41.52 \pm 4.36$ & $28-45$ & $4.61 \pm 0.48$ & $1-5$ \\
\hline Mother-nurse partnership & $149.41 \pm 18.25$ & $103-170$ & $4.39 \pm 0.53$ & $1-5$ \\
\hline Reciprocity & $39.77 \pm 5.33$ & $23-45$ & $4.42 \pm 0.59$ & $1-5$ \\
\hline Professional knowledge and skills & $31.16 \pm 4.02$ & $19-35$ & $4.45 \pm 0.57$ & $1-5$ \\
\hline Sensitivity & $26.13 \pm 3.68$ & $16-30$ & $4.35 \pm 0.61$ & $1-5$ \\
\hline Collaboration & $13.57 \pm 1.57$ & $8-15$ & $4.52 \pm 0.52$ & $1-5$ \\
\hline Communication & $16.58 \pm 2.77$ & $10-20$ & $4.15 \pm 0.69$ & $1-5$ \\
\hline Shared information & $13.16 \pm 1.85$ & $6-15$ & $4.39 \pm 0.62$ & $1-5$ \\
\hline Cautiousness & $9.05 \pm 1.06$ & $6-10$ & $4.52 \pm 0.53$ & $1-5$ \\
\hline Uncertainty & $44.72 \pm 7.72$ & $27-65$ & $2.03 \pm 0.35$ & $1-4$ \\
\hline Ambiguity & $19.74 \pm 5.15$ & $10-31$ & $1.97 \pm 0.51$ & $1-4$ \\
\hline Unpredictability & $16.98 \pm 3.00$ & $8-25$ & $2.12 \pm 0.38$ & $1-4$ \\
\hline Reliability of medical personnel & $8.00 \pm 1.60$ & $4-12$ & $2.00 \pm 4.02$ & $1-4$ \\
\hline Quality of nursing care & $174.00 \pm 17.67$ & $126-190$ & $9.16 \pm 0.93$ & $0-10$ \\
\hline Respect & $55.58 \pm 5.93$ & $37-60$ & $9.26 \pm 0.99$ & $0-10$ \\
\hline Explanation & $62.97 \pm 7.29$ & $43-70$ & $9.00 \pm 1.04$ & $0-10$ \\
\hline Kindness & $27.99 \pm 3.12$ & $16-30$ & $9.33 \pm 1.04$ & $0-10$ \\
\hline Skillfulness & $27.46 \pm 3.40$ & $17-30$ & $9.15 \pm 1.13$ & $0-10$ \\
\hline
\end{tabular}

*Average conversion score.

Table 3. Correlations between the Communication Ability of Nurses, the Mother-Nurse Partnership, Uncertainty, and the Quality of Nursing Care

\begin{tabular}{|c|c|c|c|c|}
\hline \multirow{2}{*}{ Variables } & A & $\mathrm{B}$ & $\mathrm{C}$ & $\mathrm{D}$ \\
\hline & $\mathrm{r}(p)$ & $\mathrm{r}(p)$ & $\mathrm{r}(p)$ & $\mathrm{r}(p)$ \\
\hline A. Communication ability of nurses & 1 & & & \\
\hline B. Mother-nurse partnership & $.83(<.001)$ & 1 & & \\
\hline C. Uncertainty & $-.35(<.001)$ & $-.40(<.001)$ & 1 & \\
\hline D. Quality of nursing care & $.71(<.001)$ & $.69(<.001)$ & $-.33(<.001)$ & 1 \\
\hline
\end{tabular}

Table 4. Factors That Influenced the Quality of Nursing Care as Perceived by Participants

\begin{tabular}{lccccccc}
\hline Variables & $\mathrm{B}$ & $\mathrm{SE}$ & $\beta$ & $\mathrm{t}$ & $p$ & $\mathrm{R}^{2}$ & $\mathrm{VIF}$ \\
\hline (Constant) & 2.29 & 0.47 & - & 6.08 & $<.001$ & & \\
Communication ability of nurses & 0.84 & 0.18 & .44 & 4.63 & $<.001$ & .508 & 3.22 \\
Mother-nurse partnership & 0.57 & 0.17 & .33 & 3.46 & .001 & .541 & 3.22 \\
& & & $\mathrm{R}^{2}=.541$, Adj. $\mathrm{R}^{2}=.536 \mathrm{~F}=96.69, p<.001$ & \\
\hline
\end{tabular}

VIF, variance inflation factor.

dified primary nursing delivery system. The quality of nursing care perceived by nurses in wards that use modified primary nursing was higher than that of wards that use functional nursing [22]. However, to identify the factors that result in such differences, it is also necessary to consider the demographic factors of nurses, such as career status, marital status, and education level, which have been found to cause differences in the quality of nursing care in previous studies [23]. A previous study that examined the sub-factors related to the perceived quality of nursing care found that kindness was the most highly perceived factor, followed by respect, skillfulness, and explanation ability. The kindness factor refers to the abil- 
ity of nurses to administer care for hospitalized children with sympathy and compassion [15]. In that study, the explanation factor was the lowest-rated of the sub-factors that affect the quality of nursing care perceived by mothers of hospitalized children, whereas the skillfulness factor was the lowest-rated in studies by Bae and Lee [9] and Cho et al. [15]. This is possibly due to differences in various other factors such as hospital size (including the number of beds), which nursing care delivery systems were used, and the clinical experience of nurses. Therefore, to identify various factors that affect the quality of pediatric nursing, further studies are needed to examine both the characteristics of mothers and their children and the characteristics of nurses and hospitals. One study found that mothers of hospitalized children believed explanation to be the most important factor in nursing care [16]. Mothers of hospitalized children experience fears about the hospitalization of their children and anxiety about the unfamiliar hospital environment, their hospitalized child's condition [3], and a lack of information on their child's disease and treatment. Therefore, nursing care can contribute to relieving the increased anxiety of mothers of hospitalized children, and they should be provided with education and information accordingly [9]. The quality of nursing care administered by pediatric nurses should also be improved [15], and ways to strategically improve nurses' abilities in practice to provide care-related explanations to mothers of hospitalized children should be explored.

In this study, the mean score for the communication ability of nurses perceived by the mothers (mean $=4.59$, with a possible score range of 1-5) was higher than that of a study by Lee et al. [24] (mean=4.38) in which the communication ability of nurses perceived by parents of high-risk newborns was measured using the same tool. This difference may be because, in the study by Lee et al. [24], communication between nurses and parents of high-risk newborns took place in the context of limited visiting hours in a neonatal intensive care unit. However, in this study, communication between nurses and mothers of hospitalized children occurred in a pediatric ward that presented relatively more opportunities for regular communication. In this study, the mean score for nurses' non-verbal communication ability was higher than the mean score for nurse's verbal communication ability. This result is similar to that of a study by Lee et al. [24] concerning the parents of high-risk newborns. However, a study by Kim [8] on adult inpatients found that the mean score for nurses' verbal communication ability was higher than the mean score for nurses' non-verbal communication ability. Therefore, the non-verbal communication ability of nurses is more important than their verbal communication ability in pediatric nursing than it is in adult nursing. Additionally, since the mean age of the hospi- talized children in this study was 35.9 months, pediatric nurses primarily used non-verbal communication to interact with patients. Therefore, it is more important for pediatric nurses to empathize with hospitalized children and understand them and their mothers using non-verbal expressions such as eye contact, gestures, and tone of voice rather than providing explanations in simple verbal expressions. Thus, non-verbal communication education programs should be provided to improve the non-verbal communication abilities of nurses and, in turn, the quality of nursing as perceived by mothers of hospitalized children.

In this study, the mean score for the mother-nurse partnership perceived by mothers of hospitalized children (mean= 4.39 , with a possible score range of 1-5) was similar to that of a study by Bae and Lee [9] $($ mean=4.06) that used the same tool. In this study, of the subdomains related to the mother-nurse partnership, cautiousness had the highest mean score. In this context, cautiousness refers to the sense that mothers of hospitalized children and nurses care for each other and are careful about what they say and do. Such a high level of cautiousness reflects the culture of South Korea in which people do not want to hurt others [20]. In addition, the mean score for cautiousness was also likely high due to mothers of hospitalized children wanting to receive nursing care that entailed careful consideration from nurses, warm words, and cautious behavior. Of the subdomains related to the mother-nurse partnership as perceived by mothers of hospitalized children, the mean score for communication was the lowest. Although pediatric nurses should engage children's parents in their nursing practices by using effective communication and maintaining a cooperative relationship, the results of this study reflect the reality of the situation in which nurses mostly perform one-way direct nursing without considering the needs of children and parents [25]. Therefore, to provide effective nursing care for children and families and build better partnerships, it is necessary to improve the communication abilities of pediatric nurses.

In this study, the mean score for uncertainty perceived by mothers of hospitalized children (mean $=2.03$, with a possible score range of 1-4) was lower than the mean scores of studies by Yoo (mean=2.65) [26] and by Oh (mean=2.37) [13] that used the same tool. The reason why perceived uncertainty was low in this study was likely because this study primarily involved mothers whose children were hospitalized during an acute phase of illness at a single children's hospital, whereas the participants in the studies by Yoo [26] and Oh [13] were mothers whose children were hospitalized at university hospitals and had severe or chronic diseases. After examining the scores for the subdomains of uncertainty, the mean score for unpredictability was found to be the highest, followed by the 
reliability of medical personnel and ambiguity. However, in a study by Oh (mean=2.77) [10] on the parents of children who visited pediatric wards as outpatients or who were admitted to an emergency room, the mean score for uncertainty was higher than that of this study. In addition, although Oh's study [10] included only the parents of patients with acute diseases, scores for perceived uncertainty were higher for parents of children who were admitted to an emergency room than for parents of pediatric outpatients. These findings indicate that, even for parents of children with acute diseases, perceived uncertainty may increase depending on the environments of the wards they visited, their unique hospitalization situation, and the progress and severity of their child's disease. Therefore, further studies are needed to investigate uncertainty perceived by mothers of hospitalized children that consider their specific hospitalization situations, include patients in inpatient wards, and account for the severity of children's conditions.

Our results revealed that the communication ability of nurses and the mother-nurse partnership were the factors that most affected the quality of nursing care as perceived by mothers of hospitalized children. The total explanatory power of these two factors was $54.1 \%$. The communication ability of nurses perceived by mothers of hospitalized children was found to have the greatest effect on the quality of nursing care. That is, a more positive perception of the communication ability of nurses by mothers of hospitalized children was associated with a more positive perception of the quality of nursing care. Since there have been few previous studies on the communication ability of nurses and the quality of nursing care as perceived by mothers of hospitalized children, it is difficult to compare our results to those of previous studies. However, a study by Kim [8] that examined the relationship between the communication ability of nurses and satisfaction with nursing service-a factor that is similar to the quality of nursing care-found that higher scores for the communication abilities of nurses were associated with higher scores for satisfaction with nursing service, which supports our results. Therefore, to improve the quality of nursing care perceived by mothers of hospitalized children, it is necessary to develop communication improvement programs for pediatric nurses to enhance their communication abilities. In this study, the communication skills of nurses encompass interactions between parents and nurses through verbal and non-verbal communication [19]. This is distinct from the fragmentary contents of communications, which is a subdomain of the mothernurse partnership, in which parents talk to nurses about their discomfort or their children's health status [20]. Considering that the targets of nursing care are children and their families, communication skills should account for nonverbal commu- nication methods for children with undeveloped language skills.

According to our results, one of the factors that affected the quality of nursing care was the mother-nurse partnership as perceived by mothers of hospitalized children. This finding is consistent with that of a study by Bae and Lee [9], which found that the mother-nurse partnership affected mothers of hospitalized children's perception of the quality of nursing care. Additionally, a study by Choi and Bang [20] found that a better partnership between pediatric nurses and the parents of hospitalized children was associated with higher satisfaction with nursing service, which is a similar factor to the quality of nursing care. Therefore, to improve the quality of nursing perceived by mothers of hospitalized children, mother-nurse partnership promotion programs should be developed, and their effects should be examined. More specifically, considering that explanation was the subdomain of quality of nursing care and the mother-nurse partnership with the poorest perception by mothers of hospitalized children, it is necessary to prioritize communication ability as one of the core competencies of pediatric nurses for improving the quality of pediatric nursing.

In this study, uncertainty was correlated with the quality of nursing care, but that does not necessarily mean that it affected the quality of nursing care in a causal sense. The quality of nursing care is affected by factors such as nurses' characteristics (nurse resilience) and organizational and environmental characteristics (nursing organizational culture, the nursing delivery system, and the nursing working environment) [23, 27]. Therefore, in the future, it will be necessary to examine the influence of various factors-including but not limited to uncertainty-on the quality of nursing care. The principal limitation of this study is that it is difficult to generalize the results since the subjects were all children with acute illnesses who were below preschool age and treated at a single hospital. In addition, various factors such as the characteristics of nurses and the characteristics of nursing jobs that affect the quality of nursing were not taken into account. Therefore, in the future, it is necessary to expand the pool of research subjects to include school-aged hospitalized children and adolescents with severe and chronic diseases in hospitals of various levels and to examine the quality of nursing care using various factors as predictive variables.

\section{CONCLUSION}

This descriptive research study aimed to examine the factors that affect the quality of nursing care as perceived by mothers of hospitalized children and provide basic data for the development of programs aimed at improving the quality 
of nursing care. Factors that affected the quality of nursing care perceived by mothers of hospitalized children included the communication ability of nurses and the mother-nurse partnership. Higher scores for nurses' communication abilities and the mother-nurse partnership were associated with more positive perceptions of the quality of nursing care. Therefore, to improve the quality of pediatric nursing, strategies should be explored for improving the communication abilities of nurses and the partnership between nurses and mothers of hospitalized children.

\section{ORCID}

Ina Jin

Hun Ha Cho

https://orcid.org/0000-0003-4413-9576

https://orcid.org/0000-0001-9702-0590

\section{Authors' contribution}

Conceptualization: all authors; Data collection, Formal analysis: all authors; Writing-original draft, Writing-review and editing: all authors; Final approval of published version: all authors.

\section{Conflict of interest}

No existing or potential conflict of interest relevant to this article was reported.

\section{Funding}

None.

\section{Data availability}

Please contact the corresponding author for data availability.

\section{Acknowledgements}

None.

\section{REFERENCES}

1. Statistics Korea. 2018 National fertility history and family health welfare survey [Internet]. Daejeon: Statistics Korea; 2018 [cited 2019 December 31]. Available from:

https://meta.narastat.kr/metasvc/index.do?confmNo=331001\& inputYear $=2018$

2. Health Insurance Review and Assessment Service. Medical expense statistics in 2016 [Internet]. Wonju: Health Insurance Review and Assessment Service; 2017 [cited 2017 February28]. Avail- able from:

http:// www.hira.or.kr/bbsDummy.do?pgmid=HIRAA02004503 $0000 \&$ brdScnBltNo=4\&brdBltNo=2381\&pageIndex=2\#none

3. Kim YH, Kwon BS, Kim SH, Kim JM, Park IS, Son HM, et al. Principles of paediatrics nursing. 6th ed. Paju: Soomoonsa; 2016. p. 327348.

4. Choi M, Bang K. Quality of pediatric nursing care: Concept analysis. Journal of Korean Academy of Nursing. 2010;40(6):757-764. https://doi.org/10.4040/jkan.2010.40.6.757

5. Jung JH. The relation among the burden, anxiety and nursing needs in the hospitalized children's mother [master's thesis]. Daegu: Kyungpook National University; 2015. p. 1-43.

6. Tsironi S, Koulierakis G. Factors affecting parents' satisfaction with pediatric wards. Japan Journal of Nursing Science. 2019;16(2):212220. https://doi.org/10.1111/jjns.12239

7. Lee MA, Gong SW, Cho SJ. Relationship among nursing service quality, medical service satisfaction, and hospital revisit intent. Journal of Korean Academy of Nursing Administration. 2012;18 (1):96-105.

8. Kim SH. Nurses' communication, trust in nurses, and satisfaction of nursing service perceived by inpatients [master's thesis]. Seoul: Seoul National University; 2013. p. 1-76.

9. Bae SY, Lee I. The effect of child's mother and nurse partnership on the anxiety and perceived quality of nursing care of hospitalized child's mother. Journal of the Korea Academia-Industrial cooperation Society. 2017;18(7):516-528. https://doi.org/10.5762/KAIS.2017.18.7.516

10. Oh JA. Perception of uncertainty and satisfaction for nursing service of children's parents visiting to pediatrics outpatient department and emergency room. Korean Parent-Child Health Journal. 2010;13(1):35-43.

11. Trimmer, C, Målqvist, M. Clinical communication and caregivers' satisfaction with child healthcare in Nepal; Results from Nepal Health Facility Survey 2015. BMC Health Services Research. 2019; 19:17. https://doi.org/10.1186/s12913-018-3857-4

12. Son HK, Song HB, Kim DH. Effects of the mother-medical staff partnership on mothers' condition management ability for children with chronic allergic diseases. Child Health Nursing Research. 2018;24(1):101-108.

https://doi.org/10.4094/chnr.2018.24.1.101

13. Oh JA. A study on perception of uncertainty and coping effort of hospitalized children's mother [master's thesis]. Seoul: Ewha Womans University; 1997. p. 1-79.

14. Ahn MA, Kwon M, Oh SY. A study on the convergent influencing factors of nursing service satisfaction perceived by patients and nurses. Journal of the Korea Convergence Society. 2017;8(10):135145. https://doi.org/10.15207/JKCS.2017.8.10.135

15. Cho H, Oh J, Jung D. Development of an instrument to measure the quality of care through patients' eyes for hospitalized child. Child Health Nursing Research. 2015;21(2):131-140. 
https://doi.org/10.4094/chnr.2015.21.2.131

16. Yoo SY, Kim YY, Cho H. Comparison of the quality of nursing care as perceived by pediatric nurses and mothers of hospitalized children. Child Health Nursing Research. 2018;24(4):373-382. https://doi.org/10.4094/chnr.2018.24.4.373

17. Jeong E, Kwon IS. Effect of caregiver's role improvement program on the uncertainty, stress, and role performance of caregivers with hospitalized children. Child Health Nursing Research. 2017;23(1): 70-80. https://doi.org/10.4094/chnr.2017.23.1.70

18. Heo J. The right sample size using IBMSPSS Sample Power. Seoul: Hannarae; 2013. p. 1-208.

19. Kim YK, Yu JP. A study on verbal and non-verbal communication of medical service provider. Journal of Korea Service Management Society. 2008;9(1):225-258. https://doi.org/10.15706/jksms.2008.9.1.010

20. Choi MY, Bang KS. Development and testing of a pediatric nurse parent partnership scale. Journal of Korean Academy of Nursing. 2013;43(2):194-202. https://doi.org/10.4040/jkan.2013.43.2.194

21. Mishel MH. Parent's perception of uncertainty concerning their hospitalized child. Nursing Research.1983;32(6):324-330. https://doi.org/10.1097/00006199-198311000-00002

22. Kim JY, Park BH, Ko YK. The status nursing care delivery system and the influencing factors on quality of nursing care. Korea Journal of Hospital Management. 2016;21(2):24-36.
23. Shin ES, An M, Choi ML, Lee AK, Jeon EA, Jeoung YM, et al. Factors influencing quality of nursing service among clinical nurses: Focused on resilience and nursing organizational culture. Journal of Korean Clinical Nursing Research. 2017;23(3):302-311. https://doi.org/10.22650/JKCNR.2017.23.3.302

24. Lee $\mathrm{CH}$, Jang MH, Choi YS, Shin H. The relationship between parental stress and nurses' communication as perceived by parents of high-risk newborns. Child Health Nursing Research. 2019;25(2): 184-195. https://doi.org/10.4094/chnr.2019.25.2.184

25. Youn SJ, Noh JH. The influence of emotional labor and self-efficacy of nurses at children's hospital on their partnership with parents. Journal of Korean Academic Society of Home Health Care Nursing. 2018;25(1):15-24. https://doi.org/10.22705/jkashcn.2018.25.1.015

26. Yoo KH. A study on the uncertainty and depression in mothers of hospitalized children. Journal of Korean Academic Society of Nursing Education. 2013;19(2):265-272.

https://doi.org/10.5977/jkasne.2013.19.2.265

27. Kim MS, Shin SH, Seo E. The influences of self-leadership, role conflict, nursing work environment on nursing service quality in comprehensive nursing care service wards. Journal of East-West Nursing Research. 2021;27(1):22-31.

https://doi.org/10.14370/jewnr.2021.27.1.22 